\title{
Body Mass Index and High-Density Lipoproteins in Cherokee Indian Children and Adolescents
}

\author{
PIERS R. BLACKETT, KATHLEEN S. BLEVINS, MARTHA STODDART, WENYU WANG, \\ ELAINE QUINTANA, PETAR ALAUPOVIC, AND ELISA T. LEE
}

\begin{abstract}
Department of Pediatrics [P.R.B.], Center for American Indian Health Research, College of Public Health [K.S.B., M.S., W.W., E.T.L.], University of Oklahoma Health Sciences Center, Oklahoma City, OK 73104, Hastings Indian Hospital [E.Q.], Tahlequah, OK 74464, Oklahoma Medical Research Foundation [P.A.],
\end{abstract} Oklahoma City, OK 73104

\begin{abstract}
Native Americans are predisposed to insulin resistance and associated cardiovascular risk. Therefore, we studied whether BMI (body mass index) in a population of Cherokee children and adolescents is associated with HDL-C (HDL cholesterol), and the HDL particles Lp (lipoprotein) A-I and LpA-I:A-II. Subjects were grouped by BMI Z score quartiles within three genderspecific age brackets $(5-9,10-14$, and $15-19$ y) to examine for trends in lipoprotein and HOMA-IR (homeostasis index insulin resistance) values associated with adiposity and age. HDL-C decreased by BMI Z score quartiles in all three age groups for both genders. HDL-C, LpA-I, and LpA-I:A-II decreased with age in boys but not girls. Log HOMA-IR increased by BMI Z score quartiles in all three age groups for both genders. Linear regression modeling showed BMI Z score, triglyceride, and age to be associated with HDL-C, whereas HOMA-IR was associated with LpA-I:A-II but not with HDL-C or LpA-I. When waist circumference was substituted for BMI Z score in the same models, it
\end{abstract}

\section{ABSTRACT}

was associated with HDL-C and both lipoprotein particles. In conclusion, adiposity is more associated with HDL-C lowering than with declines in the lipoprotein particles. HOMA-IR is less associated with HDL-C but may selectively influence LpA-I:AII. Greater decreases in HDL-C, LpA-I, and LpA-I:A-II with age in boys is attributed to gender-specific hormonal changes. The early onset of HDL lowering in these Native American children and adolescents, particularly boys, warrants intervention strategies to prevent obesity and associated cardiovascular risk.

(Pediatr Res 58: 472-477, 2005)

BMI, body mass index

HDL-C, high-density lipoprotein cholesterol

HOMA-IR, homeostasis index insulin resistance

Lp, lipoprotein
Because low HDL-C is a known predictor of cardiovascular disease $(1,2)$ and high levels are protective (3) in adult populations, it follows that low levels in childhood may increase cardiovascular risk at an early age. This is supported by postmortem studies on the formation of atherosclerotic plaques at ages 15-34 y in the Pathologic Determinants of Atherosclerosis in Youth (PDAY) study, in which the size and composition of the plaques were influenced by the HDL-C levels (4). Decreases in HDL-C occur with increasing BMI in men (5) and women (6). Also, BMI was inversely correlated with HDL-C in Pima Indian men and women (7). Because Native American

Received October 28, 2004; accepted January 19, 2005

Correspondence: Piers R. Blackett, M.D., 2426A, Children's Hospital of Oklahoma, 940 NE 13th St., University of Oklahoma Health Sciences Center, Oklahoma City, OK 73104; e-mail: piers-blackett@ouhsc.edu

The Cherokee Diabetes Study is supported by grant R01 DK47920 from the National Institute of Diabetes and Digestive and Kidney Diseases, Bethesda, MD.The opinions expressed in this paper are those of the authors and do not necessarily reflect the views of the Cherokee Nation. populations are prone to obesity in association with insulin resistance $(8,9)$, we investigated whether BMI would influence HDL at a young age.

LpA-I, the lipoprotein particle containing apoA-I and devoid of apoA-II, has previously been shown to protect against atherosclerosis $(10-12)$. Low apoA-I, contained in both LpA-I and LpAI:A-II, is also known to be predictive of myocardial infarction (13). In 5-17-y-old children in Bogalusa, Louisiana, the association between obesity and HDL-C was stronger than with apoA-I and appeared to be secondary to increased triglyceride (14). This was supported by the observation that increases in triglyceride alter the relative cholesterol content of HDL particles (15). However, less is known about the potentially atherogenic influence of obesity on HDL-C and the HDL particles.

The Cherokee, like other Native Americans, are at significantly increased risk for type 2 diabetes (8), which is preceded by insulin resistance $(9,16)$. Furthermore, the insulin-resistant state occurs in childhood (17), associated with obesity (18), which predicts cardiovascular risk in young adulthood (17). We studied Cherokee children and adolescents aged 5-19 y to 
determine how obesity is associated with HDL-C, LpA-I, and LpA-I:A-II.

\section{METHODS}

Subjects. With permission and collaboration of the Cherokee tribal authorities, 3690 eligible tribal members aged 5-40 y were selected from the rolls of the Cherokee Nation Registration Department. Enrollment is historically based on descent from original members who were enrolled in the early 20th century (19). Of those who were available for recruitment as previously described (20), 2205 volunteered, representing a participation rate of approximately $60 \%$. The subjects had variable self-reported Native American heritage, which was classified as $<25 \%, 25-49.9 \%, 50-74.9 \%, 75-99.9 \%$, and $100 \%$ (21). The distribution among the five categories was $16.7 \%, 22.5 \%, 28.3 \%, 20.1 \%$, and $12.4 \%$, indicating that $60.8 \%$ had more than $50 \%$ heritage. Informed consent was obtained from each subject or his/her legal guardian following approval of the Institutional Review Boards of the University of Oklahoma Health Sciences Center and the Cherokee Nation. There were 935 participants who were aged 5-19 y. The age strata consisted of three groups, aged 5-9, 10-14, and $15-19$ y. Those with diabetes $(n=11,1$ with type 1 and 10 with type 2$)$ or impaired fasting glucose $(n=7)$ as defined by the American Diabetes Association were excluded from this analysis because hyperglycemia and treatments for diabetes may influence HDL-C. After excluding the 18 subjects, 917 were studied. The prevalence of type 2 diabetes was found to be lower than that reported for the Arizona Pima but higher than in Native American children and adolescents in Manitoba $(21,22)$

Anthropometric measurement. Weight and height were measured using an electronic scale and a stadiometer. BMI was calculated as weight in kilograms divided by the height in meters squared. Duplicate measures of waist and hip circumferences were obtained

Lipids, apolipoproteins, glucose, and insulin. Fasting plasma specimens were collected for glucose, insulin, lipids, and lipoproteins. An Abbott VPSuper System automatic analyzer and commercial reagents (Abbott Laboratories, Abbott Park, IL) were used to determine levels of glucose, total cholesterol (Roche Molecular Biochemicals, Mannheim, Germany), and triglyceride (Bayer Corp., Elkhart, IN) by enzymatic methodology. HDL-C was measured following the heparin-manganese precipitation procedure of the Lipid Research Clinics Program $(23,24)$.

LpA-I and LpA-I:A-II were separated by immunoaffinity chromatography on an anti-apoA-II immunosorber before apoA-I assay (25). The original volume of whole plasma was retained in the assay, and the quantities of both LpA-I and LpA-I:A-II were expressed in milligrams of apoA-I per deciliter. Insulin levels were determined in the National Institutes of Health core laboratory at the Endocrinology Department, University of Chicago, Chicago, IL. Insulin was measured in serum samples by an overnight competitive double antibody RIA with a modification (26). HOMA-IR, an index of insulin sensitivity (27), was computed from the product of insulin $(\mu \mathrm{U} / \mathrm{mL})$ and glucose $(\mathrm{mmol} / \mathrm{L})$, divided by 22.5 .

Data Analysis. The Z score for BMI was derived using National Health and Nutrition Examination survey (NHANES) normal values for BMI for age (http://www.cdc.gov/nchs/data/nhanes/growthcharts/zscore/zbmiage.txt) (28). Owing to the wide range of values with nonparametric distribution, HOMA-IR values and triglyceride underwent log transformation. Cholesterol, log triglyceride, HDL-C, LpA-I, and LpA-I:A-II were grouped by quartiles for BMI Z score. The values in the BMI Z score quartiles for each of three age brackets $(5-9,10-14$, and $15-19$ y) and gender were assessed for change by trend analysis. Pearson correlations were performed to assess relationships between indices of adiposity and lipid and lipoprotein parameters. Multiple regression analysis was performed in three separate models with HDL-C, LpA-I, and LpA-I:A-II as the dependent variables and age, gender, BMI Z score, and HOMA-IR as the independent variables. The independent variables were selected as being potentially associated with HDL-C and the HDL lipoproteins. Because waist circumference correlates with BMI, both were examined as an independent variables in separate models to compare the association of BMI Z score and waist circumference with HDL-C, LpA-I, and LpA-I:A-II.

\section{RESULTS}

The means \pm SD for BMI, insulin, glucose, lipids, and apolipoproteins are listed in Table 1. HDL-C for both genders (Figs. 1and 2) decreased successively in BMI Z score quartiles $(p<0.0001$ for trend). Declines in LpA-I and LpA-I:A-II by BMI Z score quartile were less significant (Table 2). There were significant trends for declines in LpA-I and LpA-I:A-II for girls aged $15-19$ y $(p<0.05)$ and boys aged 10-14 y $(p<$ 0.01 ). LpA-I:A-II also declined in 15-19-y-old boys (Table 2, $p<0.05)$.

Boys showed a significant trend for decline in HDL-C with age group in the first quartile ( $p<0.05$ for trend), second quartile $(p<0.0001)$, and third quartile $(p<0.001)$, but the trend was not evident in girls (Figs. 1 and 2). Similar declines with age in boys occurred for LpA-I $(p<0.05$ for trend in all quartiles) and LpA-I:A-II ( $p<0.05$ for trend in the 2nd, 3rd, and 4th quartiles, Table 2).

Log HOMA-IR increased for each BMI Z score quartile in each age group for both genders $(p<0.0001$ for trend, Table 3). Log HOMA-IR also increased with age in both genders ( $p$ $<0.01$ for trend except for girls in the 3rd BMI Z score quartile, Table 3).

Correlation coefficients $(r)$ for inverse correlations $(p<$ 0.001) of HDL-C, LpA-I, and LpA-I:A-II with BMI Z score, waist circumference, and HOMA-IR were higher in boys than girls (Table 4). Correlation coefficients for waist circumference with HDL-C, LpA-I, and LpA-I:A-II were higher than for BMI $\mathrm{Z}$ score in both genders, although the $p$ value remained the same $(p<0.001)$.

Multiple linear regression modeling with BMI Z score, log triglyceride, log HOMA-IR, age, and gender as independent variables showed the following (Table 5): Model 1-With HDL-C as the dependent variable, BMI Z score, triglyceride, and age were significant associations. Model 2-With LpA-I

Table 1. Mean values \pm 1 SD for BMI, waist circumference, insulin, glucose, triglyceride, cholesterol, HDL-C, LpA-I, and LpA-I:A-II for both genders in each age group

\begin{tabular}{|c|c|c|c|c|c|c|}
\hline & \multicolumn{2}{|c|}{$5-9 y$} & \multicolumn{2}{|c|}{$10-14$ y } & \multicolumn{2}{|c|}{$15-19 y$} \\
\hline & Boys & Girls & Boys & Girls & Boys & Girls \\
\hline Number & 124 & 132 & 180 & 188 & 130 & 163 \\
\hline Waist $(\mathrm{cm})$ & $65.3(14.0)$ & $63.2(10.4)$ & $77.9(15.4)$ & $77.6(14.1)$ & $90.4(15.6)$ & $84.8(14.2)$ \\
\hline Insulin $(\mu \mathrm{U} / \mathrm{mL})$ & $14.2(18.0)$ & $13.7(9.0)$ & $21.9(18.5)$ & $24.6(22.0)$ & $21.7(15.5)$ & $24.3(23.6)$ \\
\hline Glucose $(\mathrm{mmol} / \mathrm{L})$ & $4.65(0.46)$ & $4.45(.4)$ & $4.68(0.49)$ & $4.58(0.42)$ & $4.69(0.57)$ & $4.41(0.5)$ \\
\hline HDL-C (mmol/L) & $1.24(0.3)$ & $1.17(0.26)$ & $1.11(0.25)$ & $1.09(0.24)$ & $1.02(0.23)$ & $1.12(0.23)$ \\
\hline LpA-I (mg/dL) & $27.2(4.5)$ & $25.8(4.0)$ & $25.0(4.4)$ & $24.4(4.4)$ & $23.5(4.2)$ & $25.1(4.9)$ \\
\hline LpA-I:A-II (mg/dL) & $94.4(12.4)$ & $92.0(12.2)$ & $90.0(11.2)$ & $86.4(10.9)$ & $86.3(12.7)$ & $89.2(15.8)$ \\
\hline
\end{tabular}




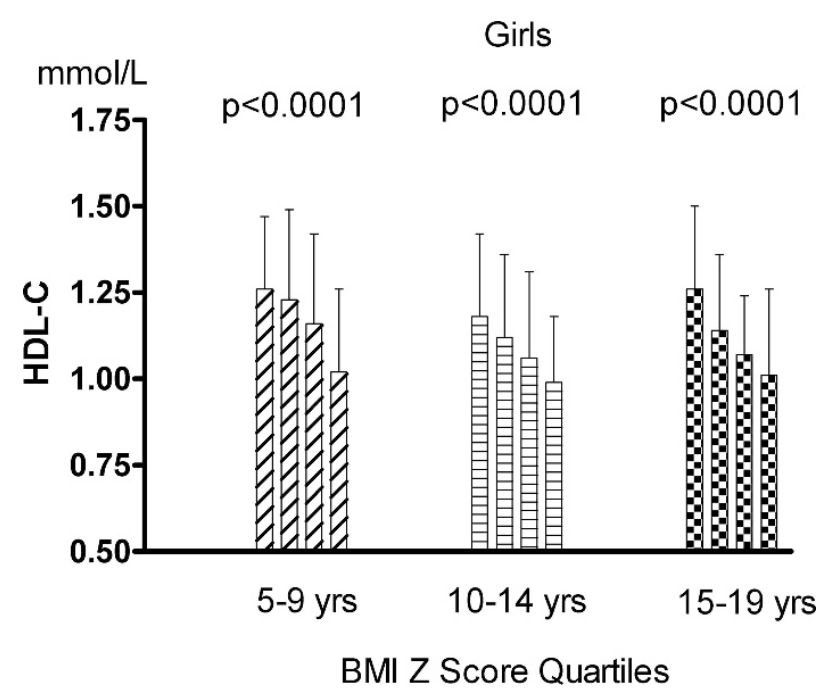

Figure 1. HDL-C in BMI Z score quartiles for 5-9, 10-14, and 15-19-y-old girls. Trend for significant change in HDL-C by quartile is indicated by $p$ values above the bars ( $p<0.0001$ for all age groups). The trend for change in HDL-C with age group was not significant.

as the dependent variable, BMI Z score and age were associated. Model 3-With LpA-I:A-II as the dependent variable, log HOMA-IR, BMI Z score, and age were associated. When waist was substituted for BMI Z score as an independent variable (Table 6): Model 4-With HDL-C as the dependent variable, waist and triglyceride were associated. Model 5-With LpA-I as the dependent variable, only waist was associated. Model 6-With LpAI:LpA-II as the dependent variable, only waist was associated.

\section{DISCUSSION}

Decline in HDL-C values with BMI Z score quartiles was significant for all age groups of Cherokee children and adolescents, but declines in LpA-I and LpA-I:A-II were less remarkable. The finding is analogous to a predominant decrease in the

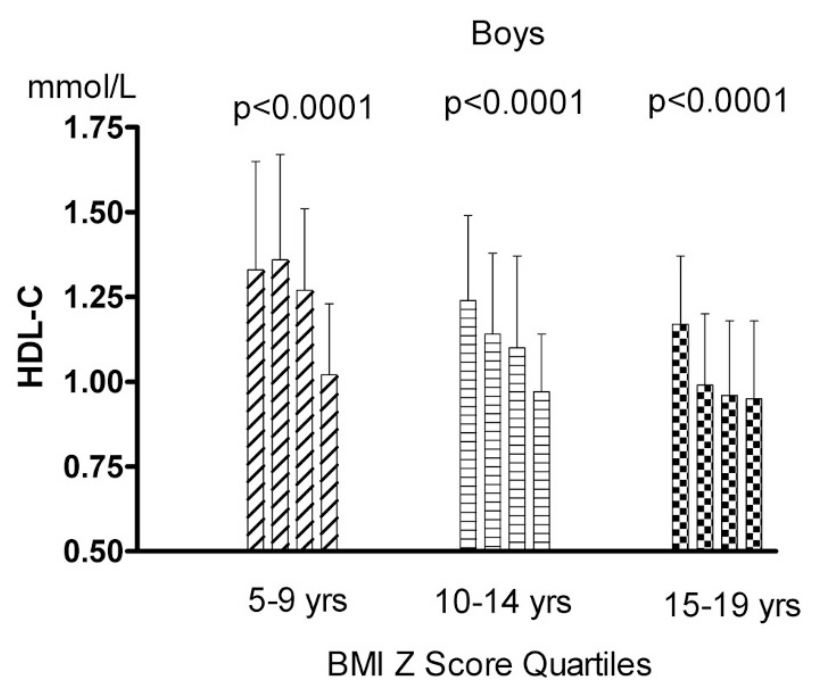

Figure 2. HDL-C in BMI Z score quartiles for 5-9, 10-14, and 15-19-y-old boys. Trend for significant change in HDL-C by quartile is indicated by $p$ values above the bars $(p<0.0001$ for all age groups). Significant change in HDL-C with age group was observed for the first quartile $(p<0.05)$, second quartile $(p<0.0001)$, and third quartile $(p<0.001)$. cholesterol "load" for the respective lipoprotein "transport vehicles," which remain relatively constant. Adiposity may therefore result in less transfer of cholesterol to the HDL particles. The decreased cholesterol supply could be derived from cells mediated by ABCA1 or from lipolysis of VLDL by lipoprotein lipase and hepatic lipase. Although the ABCA1, located on cell surfaces, has an important role in early HDL formation, it does not contribute to the low HDL-C in subjects with a low HDL-C (29) or with the metabolic syndrome (30). However, cholesterol efflux from cells via ABCA1 has recently been shown to be responsive to insulin (31), suggesting that insulin resistance could reduce efflux. Lower LPL activity could result from insulin resistance since it is an insulin-sensitive enzyme requiring insulin to promote synthesis (32). A decrease in LPL activity results in impaired cholesterol transfer from the non-HDL lipoproteins to HDL during lipolysis (33). This appears possible even in the youngest age group, aged 5-9 y, since HOMA-IR increased by BMI-Z score quartile for all age groups.

The BMI Z score was also significantly associated with both LpA-I and LpA-I:A-II in multiple regression models, supporting a role for adiposity in influencing the HDL particles. It is of interest that, although HOMA-IR was included in the model, it was not associated with HDL-C or LpA-I, but was inversely associated with LpA-I:A-II. Thus, the HDL particles containing both apoA-I and apoA-II appear to be negatively influenced by insulin resistance. These findings can be explained by increased cholesterol uptake from HDL by SR-BI scavenger receptors, which is known to be selectively greater from LpAI:A-II particles (34), making them susceptible to degradation. The fractional catabolic rate for apoA-I is increased in cases with insulin resistance (35) but not so for apoA-II (36). However, apoA-II production is considered to be a determinant of LpA-I:A-II (37) but is not different in the insulin-resistant state (36).

Additionally, multiple regression modeling supported a role for triglyceride in HDL-C lowering (39). This can partly be attributed to less cholesterol transfer (40) during lipoprotein lipase-induced catabolism of triglyceride-rich lipoproteins (41) as insulin resistance increases. In addition, triglyceride, when elevated, may enrich HDL due to the action of cholesterol ester transport protein (CETP) (42). HDL then becomes a substrate for catabolism by hepatic triglyceride lipase (43). However, the relatively lower triglyceride levels compared with levels seen in adults may have been less contributory in this population.

Significant decreases in HDL-C and HDL particles with age occurred in adolescent boys but not in girls and may contribute to enhanced risk for coronary artery disease known to occur in men compared with women (3). This was probably not associated with insulin resistance inasmuch as HOMA-IR increased similarly after age $10 \mathrm{y}$ in both genders, whereas the genderrelated decreases in HDL measures were more evident in boys. Previous observations have shown a decrease in HDL-C for African American and Caucasian boys more than girls during adolescence (44-46) and a decline mainly occurring in large HDL particles particularly in boys (47). Gender differences in the age-related changes in HDL particles and HDL-C coin- 
Table 2. LpA-I and LPA-I:A-II are arranged in BMI Z score quartiles for 5-9, 10-14, and 15-19-y-old girls and boys

\begin{tabular}{|c|c|c|c|c|c|}
\hline & \multicolumn{4}{|c|}{ BMI Z Score Quartiles } & $\begin{array}{l}p \text { for trend } \\
\text { by quartiles }\end{array}$ \\
\hline \multicolumn{6}{|l|}{$\mathrm{LpA}-\mathrm{I}, \mathrm{mg} / \mathrm{dL}$} \\
\hline $5-9 y$ & $26.2 \pm 4.1$ & $25.9 \pm 3.1$ & $25.7 \pm 3.9$ & $25.4 \pm 5.0$ & 0.4083 \\
\hline $10-14 y$ & $24.3 \pm 4.3$ & $25.0 \pm 4.3$ & $24.7 \pm 5.2$ & $23.7 \pm 3.6$ & 0.4362 \\
\hline $15-19$ y & $26.7 \pm 5.3$ & $25.4 \pm 4.5$ & $24.3 \pm 4.0$ & $24.4 \pm 5.0$ & 0.0166 \\
\hline $5-9$ y & $27.6 \pm 4.4$ & $27.1 \pm 4.2$ & $29.2 \pm 4.7$ & $25.3 \pm 3.6$ & 0.1691 \\
\hline $10-14$ y & $26.6 \pm 4.1$ & $25.0 \pm 4.6$ & $24.7 \pm 4.3$ & $23.7 \pm 4.0$ & 0.0025 \\
\hline $15-19 y$ & $24.6 \pm 3.3$ & $22.6 \pm 4.0$ & $23.7 \pm 4.3$ & $23.0 \pm 4.4$ & 0.2479 \\
\hline$p$ for trend by age & 0.0041 & $<0.0001$ & $<0.0001$ & 0.0266 & \\
\hline \multicolumn{6}{|l|}{ LpA-I:A-II, mg/dL } \\
\hline \multicolumn{6}{|l|}{ Girls } \\
\hline \multicolumn{6}{|l|}{ Boys } \\
\hline $5-9 y$ & $95.7 \pm 10.0$ & $97.1 \pm 13.8$ & $95.4 \pm 14.3$ & $90.3 \pm 9.9$ & 0.0698 \\
\hline $10-14$ y & $94.3 \pm 10.5$ & $89.8 \pm 10.3$ & $89.8 \pm 13.4$ & $86.4 \pm 9.3$ & 0.0017 \\
\hline $15-19 \mathrm{y}$ & $90.3 \pm 12.4$ & $85.9 \pm 13.1$ & $84.5 \pm 12.5$ & $84.0 \pm 11.4$ & 0.0378 \\
\hline$p$ for trend by age & 0.0550 & 0.005 & 0.0017 & 0.0148 & \\
\hline
\end{tabular}

Significance ( $p$ values) for trend to change by quartile are listed in the last column. Significance ( $p$ values) for trend to change by age group are listed in the fourth rows.

cided with ages of expected pubertal development. This is supported by the known temporal sequence of changes with gender-specific pubertal onset and progression (48), suggesting that the changes could be accounted for by sex hormones.

Testosterone levels in mature females remain low and are similar to those in boys during early stages of puberty (49), but the increased estrogens appear to override the androgen effect on HDL particle degradation. In contrast, boys have an increase in testosterone at age 11 y (50) and the rise continues during puberty (50), coinciding with a continued decrease in HDL. Therefore, testosterone-induced increase in hepatic triglyceride lipase activity (51) may account for the lower HDL-C (52) in boys because $\mathrm{HDL}_{2}$ is a known substrate (53). In contrast, the sustained apoA-I levels in adolescent girls can be attributed to the influence of estrogen $(54,55)$. Studies in Bogalusa showed that LpA-I was higher in girls than boys from age 14 to $17 \mathrm{y}$ and tended to show a cross-over effect because LpA-I levels in girls decrease before pubertal onset coinciding with adrenal adrenarche, but the levels exceed those in boys at about age $14 \mathrm{y}$ (56). We confirmed that decreases in both LpA-I and LpA-I:A-II occur in both genders during the early pubertal years (56) but that a decrease after age $15 \mathrm{y}$ is more evident in boys than girls.

Because waist circumference has been established as a single measure of visceral adiposity in adults (57) and children (58), we evaluated it as a determinant of HDL cholesterol, LpA-I, and LpA-I:A-II. Good correlation and association in regression modeling support a compounding influence of visceral fat on the tendency to decrease HDL with age. Visceral fat is associated with low HDL-C and hypertriglyceridemia in adults (59) and in adolescents (60), and men tend to deposit more than women $(61,62)$, possibly accounting for increased

Table 3. Log HOMA-IR $\pm S D$ arranged in BMI Z score quartiles for 5-9, 10-14, and 15-19-y-old girls and boys

\begin{tabular}{|c|c|c|c|c|c|}
\hline & \multicolumn{4}{|c|}{ BMI Z Score Quartiles } & $\begin{array}{l}p \text { for trend } \\
\text { by quartiles }\end{array}$ \\
\hline \multicolumn{6}{|l|}{ Log HOMA-IR } \\
\hline $5-9 y$ & $0.5 \pm 0.5$ & $0.6 \pm 0.6$ & $1.0 \pm 0.6$ & $1.2 \pm 0.5$ & $<0.0001$ \\
\hline $10-14 \mathrm{y}$ & $0.8 \pm 0.5$ & $1.2 \pm 0.4$ & $1.5 \pm 0.5$ & $2.0 \pm 0.6$ & $<0.0001$ \\
\hline $15-19 y$ & $0.9 \pm 0.6$ & $1.1 \pm 0.5$ & $1.2 \pm 0.6$ & $2.0 \pm 0.6$ & $<0.0001$ \\
\hline $5-9 y$ & $0.4 \pm 0.6$ & $0.3 \pm 0.5$ & $0.7 \pm 0.7$ & $1.5 \pm 0.8$ & $<0.0001$ \\
\hline $10-14 y$ & $0.8 \pm 0.5$ & $1.0 \pm 0.5$ & $1.3 \pm 0.6$ & $1.9 \pm 0.5$ & $<0.0001$ \\
\hline $15-19 y$ & $0.8 \pm 0.5$ & $1.1 \pm 0.6$ & $1.4 \pm 0.5$ & $2.0 \pm 0.5$ & $<0.0001$ \\
\hline$p$ for trend by age & 0.0004 & $<0.0001$ & $<0.0001$ & 0.0068 & \\
\hline
\end{tabular}

Significance ( $p$ values) for trend to change by quartile are listed in the last column. Significance ( $p$ values) for trend to change by age group are listed in the fourth rows. 
Table 4. $R$ values for Pearson correlations of HDL-C, LpA-I, and LPA-I:A-II with BMI Z score, waist circumference, and HOMA-IR

\begin{tabular}{|c|c|c|c|c|c|c|}
\hline & \multicolumn{2}{|c|}{ BMI Z Score } & \multicolumn{2}{|c|}{ Waist } & \multicolumn{2}{|c|}{ HOMA-IR } \\
\hline & Girls & Boys & Girls & Boys & Girls & Boys \\
\hline HDL-C & $-0.30 *$ & $-0.38^{*}$ & $-0.31 *$ & $-0.46^{*}$ & $-0.30 *$ & $-0.35^{*}$ \\
\hline LpA-I & -0.08 & $-0.18^{*}$ & -0.12 & $-0.30 *$ & $-0.10 \S$ & $-0.21 *$ \\
\hline LpA-I:A-II & -0.09 & $-0.20 *$ & $-0.16^{*}$ & $-0.30 *$ & -0.15 II & $-0.24 *$ \\
\hline
\end{tabular}

$* p<0.001$

II $p<0.01$

$\S p<0.05$

vascular risk in men (61). It is first acquired in childhood and is proportionate to a general increase in body fat (63). When present in adolescence, it is associated with postmortem evidence of coronary artery pathology (64), suggesting its importance as a therapeutic target because it is potentially reversible, particularly in men (65). Comparative ethnic studies in childhood suggest a higher proportion of visceral fat in Caucasians than African Americans (66), but accumulation in Native Americans appears to be similar to Caucasians (67). The influence on insulin resistance may be of more significance in Native Americans in view of their predisposition to diabetes.

We conclude that the obesity-related lowering of HDL-C and its constituent lipoproteins begins in 5-9 y olds. However, the effect may not be confined to those of Cherokee origin and should be compared in other ethnic groups. Multiple regression modeling supports a negative influence of adiposity on HDL-C and to a lesser extent on LpA-I and LpA-I:A-II. HOMA-IR was negatively associated with LpA-I:A-II, supporting its role as a cholesterol acceptor from lipoprotein and cellular sources.

Table 5. Multiple regression models with HDL-C (model 1), LpA-I (model 2), and LpA-I:A-II (model 3) as dependent variables. In each model, age, gender, log HOMA-IR and BMI Z score are independent variables

\begin{tabular}{|c|c|c|c|}
\hline \multicolumn{4}{|c|}{ Model 1. Dependent variable: HDL-C $\left(r^{2}=0.2449\right)$} \\
\hline Independent variable & Parameter estimate & Standard error & $p$ \\
\hline BMI Z score & -2.0859 & 0.2813 & $<0.0001$ \\
\hline Log triglyceride & -6.0847 & 0.5951 & $<0.0001$ \\
\hline Age & -0.2877 & 0.0792 & 0.0003 \\
\hline Log HOMA-IR & & & NS \\
\hline Gender & & & NS \\
\hline \multicolumn{4}{|c|}{ Model 2. Dependent variable: LpA-I $\left(r^{2}=0.0467\right)$} \\
\hline Independent variable & Parameter estimate & Standard error & $p$ \\
\hline BMI Z score & -0.5158 & 0.1318 & $<0.0001$ \\
\hline Age & -0.2011 & 0.0388 & $<0.0001$ \\
\hline Log triglyceride & & & NS \\
\hline Log HOMA-IR & & & NS \\
\hline Gender & & & NS \\
\hline \multicolumn{4}{|c|}{ Model 3. Dependent Variable: LpA-I:A-II $\left(r^{2}=0.0512\right)$} \\
\hline Independent variable & Parameter estimate & Standard error & $p$ \\
\hline Log HOMA-IR & -1.9262 & 0.6847 & 0.0050 \\
\hline BMI Z score & -1.0028 & 0.4447 & 0.0244 \\
\hline Age & -0.3689 & 0.1160 & 0.0015 \\
\hline Log triglyceride & & & NS \\
\hline Gender & & & NS \\
\hline
\end{tabular}

Table 6. Multiple regression models with waist circumference substituted for BMI Z score as an independent variable

\begin{tabular}{|c|c|c|c|}
\hline \multicolumn{4}{|c|}{ Model 4. Dependent Variable: HDL-C $\left(r^{2}=0.2391\right)$} \\
\hline Independent variable & Parameter estimate & Standard error & $p$ \\
\hline Waist & -0.1600 & 0.0194 & $<0.0001$ \\
\hline Log triglyceride & -5.7425 & 0.6020 & $<0.0001$ \\
\hline Age & & & NS \\
\hline Log HOMA-IR & & & NS \\
\hline Gender & & & NS \\
\hline \multicolumn{4}{|c|}{ Model 5. Dependent Variable: LpA-I $\left(r^{2}=0.0522\right)$} \\
\hline Independent variable & Parameter estimate & Standard error & $p$ \\
\hline Waist & -0.0578 & 0.0088 & $<0.0001$ \\
\hline Log triglyceride & & & NS \\
\hline Age & & & NS \\
\hline Log HOMA-IR & & & NS \\
\hline Gender & & & NS \\
\hline \multicolumn{4}{|c|}{ Model 6. Dependent Variable: LpA-I:A-II $\left(r^{2}=0.0596\right)$} \\
\hline Independent variable & Parameter estimate & Standard error & $p$ \\
\hline Waist & -0.1742 & 0.0249 & $<0.0001$ \\
\hline Log triglyceride & & & NS \\
\hline Age & & & NS \\
\hline HOMA-IR & & & NS \\
\hline Gender & & & NS \\
\hline
\end{tabular}

The trend for HDL-C, LpA-I, and LpA-I:A-II to decrease with age in boys more than in girls supports a gender-specific effect of puberty. The findings support an emphasis on lifestyle as a means to prevent obesity and insulin resistance in childhood, particularly in populations predisposed to obesity and insulin resistance such as the Cherokee.

Acknowledgments. The authors thank the Cherokee people and the healthcare and administrative officials of the Cherokee Nation in Tahlequah, OK, for their support and assistance. The authors also thank the administrators and staff of the Cherokee Diabetes Study, Sequoyah High School, and the Cherokee Nation clinics at Stilwell, Salina, Sallisaw, and Jay.

\section{REFERENCES}

1. Miller GJ, Miller NE 1975 Plasma-high-density-lipoprotein concentration and development of ischaemic heart-disease. Lancet 1:16-19

2. Miller NE, Thelle DS, Forde OH, Mjos OD 1977 The Tromso heart-study. Highdensity lipoprotein and coronary heart disease: a prospective case-control study. Lancet 1:965-968

3. Gordon T, Castelli WP, Hjortland MC, Kannel WB, Dawber TR 1977 High density lipoprotein as a protective factor against coronary heart disease. The Framingham Study. Am J Med 62:707-714

4. Homma S, Ishii T, Malcom GT, Zieske AW, Strong JP, Tsugane S, Hirose N 2001 Histopathological modifications of early atherosclerotic lesions by risk factorsfindings in PDAY subjects. Atherosclerosis 156:389-399

5. Denke MA, Sempos CT, Grundy SM 1993 Excess body weight. An under-recognized contributor to high blood cholesterol levels in white American men. Arch Intern Med 153:1093-1103

6. Denke MA, Sempos CT, Grundy SM 1994 Excess body weight. An under-recognized contributor to dyslipidemia in white American women. Arch Intern Med 154:401-410

7. Howard BV, Davis MP, Pettitt DJ, Knowler WC, Bennett PH 1983 Plasma and lipoprotein cholesterol and triglyceride concentrations in the Pima Indians: distributions differing from those of Caucasians. Circulation 68:714-724

8. West KM 1974 Diabetes in American Indians and other native populations of the New World. Diabetes 23:841-855

9. Weyer C, Bogardus C, Mott DM, Pratley RE 1999 The natural history of insulin secretory dysfunction and insulin resistance in the pathogenesis of type 2 diabetes mellitus. J Clin Invest 104:787-794 
10. Parra HJ, Arveiler D, Evans AE, Cambou JP, Amouyel P, Bingham A, McMaster D, Schaffer P, Douste-Blazy P, Luc JL, Richard P, Ducimetiere, Fruchart JC, Cambien F 1992 A case-control study of lipoprotein particles in two populations at contrasting risk for coronary heart disease. The ECTIM Study. Arterioscler Thromb 12:701-707

11. Genest JJ Jr., Bard JM, Fruchart JC, Ordovas JM, Wilson PF, Schaefer EJ 1991 Plasma apolipoprotein A-I, A-II, B, E and C-III containing particles in men with premature coronary artery disease. Atherosclerosis 90:149-157

12. Puchois P, Kandoussi A, Fievet P, Fourrier JL, Bertrand M, Koren E, Fruchart JC 1987 Apolipoprotein A-I containing lipoproteins in coronary artery disease. Atherosclerosis 68:35-40

13. Walldius G, Jungner I, Holme I, Aastveit AH, Kolar W, Steiner E 2001 High apolipoprotein B, low apolipoprotein A-I, and improvement in the prediction of fatal myocardial infarction (AMORIS study): a prospective study. Lancet 358:2026-2033

14. Freedman DS, Srinivasan SR, Shear CL, Webber LS, Chiang YK, Berenson GS 1987 Correlates of high density lipoprotein cholesterol and apolipoprotein A- I levels in children. The Bogalusa Heart Study. Arteriosclerosis 7:354-360

15. Leroux G, Lemieux I, Lamarche B, Cantin B, Dagenais GR, Lupien PJ, Despres JP 2000 Influence of triglyceride concentration on the relationship between lipoprotein cholesterol and apolipoprotein B and A-I levels. Metabolism 49:53-61

16. Weyer C, Hanson RL, Tataranni PA, Bogardus C, Pratley RE 2000 A high fasting plasma insulin concentration predicts type 2 diabetes independent of insulin resistance: evidence for a pathogenic role of relative hyperinsulinemia. Diabetes 49:2094-2101

17. Srinivasan SR, Myers L, Berenson GS 2002 Predictability of childhood adiposity and insulin for developing insulin resistance syndrome (syndrome $\mathrm{X}$ ) in young adulthood: the Bogalusa Heart Study. Diabetes 51:204-209

18. Reaven P, Nader PR, Berry C, Hoy T 1998 Cardiovascular disease insulin risk in Mexican-American and Anglo-American children and mothers. Pediatrics 101:E12

19. Woodward GC 1998 The Cherokees. University of Oklahoma Press, Norman, OK

20. Stoddart ML, Blevins KS, Lee ET, Wang W, Blackett PR 2002 Cherokee Diabetes Study. Association of acanthosis nigricans with hyperinsulinemia compared with other selected risk factors for type 2 diabetes in Cherokee Indians: the Cherokee diabetes study. Diabetes Care 25:1009-1014

21. Lee ET, Begum M, Wang W, Blackett PR, Blevins KS, Stoddart M, Tolbert B, Alaupovic P 2004 Type 2 diabetes and impaired fasting glucose in American Indians aged 5-40 years: the Cherokee Diabetes Study. Ann Epidemiol 14:696-704

22. Dabelea D, Hanson RL, Bennett PH, Roumain J, Knowler WC, Pettitt DJ 1984 Increasing prevalence of Type II diabetes in American Indian children. Diabetologia 41:904-910

23. The Lipid Research Clinics Coronary Primary Prevention Trial results. I. Reduction in incidence of coronary heart disease. JAMA 251:351-364

24. Lipid Research Clinics Program 1974 The Manual of Laboratory Operations for Lipid and Lipoprotein Analysis. DHEW Publication No. NIH 75-6288. National Institutes of Health, Bethesda, MD

25. Alaupovic P, Hodis HN, Knight-Gibson C, Mack WJ, LaBree L, Cashin-Hemphill L, Corder CN, Kramsch DM, Blankenhorn DH 1994 Effects of lovastatin on ApoA- and ApoB-containing lipoproteins. Families in a subpopulation of patients participating in the Monitored Atherosclerosis Regression Study (MARS). Arterioscler Thromb 14:1906-1913

26. Sobey WJ, Beer SF, Carrington CA, Clark PM, Frank BH, Gray IP, Luzio SD, Owens DR, Schneider AE, Siddle K, Temple RC, Hales CN 1989 Sensitive and specific two-site immunoradiometric assays for human insulin, proinsulin, 65-66 split and 32-33 split proinsulins. Biochem J 260:535-541

27. Gungor N, Saad R, Janosky J, Arslanian S 2004 Validation of surrogate estimates of insulin sensitivity and insulin secretion in children and adolescents. J Pediat $144: 47-55$

28. Kuczmarski RJ, Ogden CL, Guo SS, Grummer-Strawn LM, Flegal KM, Mei Z, Wei R, Curtin LR, Roche AF, Johnson CL 2000 CDC Growth Charts for the United States: methods and development. Vital Health Stat 11:1-190

29. Marcil M, Bissonnette R, Vincent J, Krimbou L, Genest J 2003 Cellular phospholipid and cholesterol efflux in high-density lipoprotein deficiency. Circulation 107:1366-1371

30. Alenezi MY, Marcil M, Blank D, Sherman M, Genest J Jr 2004 Is the decreased high-density lipoprotein cholesterol in the metabolic syndrome due to cellular lipid efflux defect? J Clin Endocrinol Metab 89:761-764

31. Sartipy P, Loskutoff DJ 2003 Expression profiling identifies genes that continue to respond to insulin in adipocytes made insulin-resistant by treatment with tumor necrosis factor-alpha. J Biol Chem 278:52298-52306

32. Sadur CN, Eckel RH 1982 Insulin stimulation of adipose tissue lipoprotein lipase. Use of the euglycemic clamp technique. J Clin Invest 69:1119-1125

33. Chajek T, Eisenberg S 1978 Very low density lipoprotein. Metabolism of phospholipids, cholesterol, and apolipoprotein $\mathrm{C}$ in the isolated perfused rat heart. J Clin Invest 61:1654-1665

34. Rinninger F, Brundert M, Budzinski RM, Fruchart JC, Greten H, Castro GR 2003 Scavenger receptor BI (SR-BI) mediates a higher selective cholesteryl ester uptake from LpA-I compared with LpA-I:A-II lipoprotein particles. Atherosclerosis 166:31-40

35. Pont F, Duvillard L, Florentin E, Gambert P, Verges B 2002 High-density lipoprotein apolipoprotein A-I kinetics in obese insulin resistant patients. An in vivo stable isotope study. Int J Obes Relat Metab Disord 26:1151-1158

36. Pietzsch J, Julius U, Nitzsche S, Hanefeld M 1998 In vivo evidence for increased apolipoprotein A-I catabolism in subjects with impaired glucose tolerance. Diabetes 47:1928-1934

37. Ikewaki K, Zech LA, Kindt M, Brewer HB Jr, Rader DJ 1995 Apolipoprotein A-II production rate is a major factor regulating the distribution of apolipoprotein A-I among HDL subclasses LpA-I and LpA-I:A-II in normolipidemic humans. Arterioscler Thromb Vasc Biol 15:306-312

38. Pietzsch J, Julius U, Nitzsche S, Hanefeld M 1998 In vivo evidence for increased apolipoprotein A-I catabolism in subjects with impaired glucose tolerance. Diabetes 47:1928-1934

39. Patsch JR, Prasad S, Gotto AM Jr, Patsch W 1987 High density lipoprotein ${ }_{2}$ Relationship of the plasma levels of this lipoprotein species to its composition, to the magnitude of postprandial lipemia, and to the activities of lipoprotein lipase and hepatic lipase. J Clin Invest 80:341-347

40. Picard F, Boivin A, Lalonde J, Deshaies Y 2002 Resistance of adipose tissue lipoprotein lipase to insulin action in rats fed an obesity-promoting diet. Am J Physiol Endocrinol Metab 282:E412-E418

41. Eisenberg S, Olivecrona T 1979 Very low density lipoprotein. Fate of phospholipids, cholesterol, and apolipoprotein C during lipolysis in vitro. J Lipid Res 20:614-623

42. Tall AR 1993 Plasma cholesteryl ester transfer protein. J Lipid Res 34:1255-1274

43. Eisenberg S 1984 High density lipoprotein metabolism. J Lipid Res 25:1017-1058

44. Morrison JA, Laskarzewski PM, Rauh JL, Brookman R, Mellies M, Frazer M, Khoury P, deGroot I, Kelly K, Glueck CJ 1979 Lipids, lipoproteins, and sexual maturation during adolescence: the Princeton maturation study. Metabolism 28:641-649

45. Beaglehole R, Trost DC, Tamir I, Kwiterovich P, Glueck CJ, Insull W, Christensen B 1980 Plasma high-density lipoprotein cholesterol in children and young adults. The Lipid Research Clinics Program Prevalence Study. Circulation 62:IV83-IV92

46. Berenson GS, Srinivasan SR, Cresanta JL, Foster TA, Webber LS 1981 Dynamic changes of serum lipoproteins in children during adolescence and sexual maturation. Am J Epidemiol 113:157-170

47. Freedman DS, Bowman BA, Srinivasan SR, Berenson GS, Otvos JD 2001 Distribution and correlates of high-density lipoprotein subclasses among children and adolescents. Metabolism 50:370-376

48. Patsch JR, Prasad S, Gotto AM Jr., Bengtsson-Olivecrona G 1984 Postprandial lipemia. A key for the conversion of high density lipoprotein ${ }_{2}$ into high density lipoprotein ${ }_{3}$ by hepatic lipase. J Clin Invest 74:2017-2023

49. Marshall WA 1976 Steroids after birth-puberty. Postgrad Med J 52:620-624

50. Faiman C, Winter JS, Reyes FI 1976 Patterns of gonadotrophins and gonadal steroids throughout life. Clin Obstet Gynaecol 3:467-483

51. Mowri HO, Patsch W, Smith LC, Gotto AM Jr., Patsch JR 1992 Different reactivities of high density lipoprotein ${ }_{2}$ subfractions with hepatic lipase. J Lipid Res 33:1269-1279

52. Tikkanen MJ, Nikkila EA 1987 Regulation of hepatic lipase and serum lipoproteins by sex steroids. Am Heart J 113:562-567

53. Breckenridge WC, Little JA, Alaupovic P, Wang CS, Kuksis A, Kakis G, Lindgren F, Gardiner G 1982 Lipoprotein abnormalities associated with a familial deficiency of hepatic lipase. Atherosclerosis 45:161-179

54. Laskarzewski PM, Morrison JA, Gutai J, Khoury PR, Glueck CJ 1983 Longitudinal relationships among endogenous testosterone, estradiol, and Quetelet index with high and low density lipoprotein cholesterols in adolescent boys. Pediatr Res 17:689-698

55. Srinivasan SR, Sundaram GS, Williamson GD, Webber LS, Berenson GS 1985 Serum lipoproteins and endogenous sex hormones in early life: observations in children with different lipoprotein profiles. Metabolism 34:861-867

56. Srinivasan SR, Elkasabany A, Berenson GS 1998 Distribution and correlates of serum high-density lipoprotein subclasses (LpA-I and LpA-I:A-II) in children from a biracial community. The Bogalusa Heart Study. Metabolism 47:757-763

57. Ford ES, Mokdad AH, Giles WH 2003 Trends in waist circumference among U.S adults. Obes Res 11:1223-1231

58. Fernandez JR, Redden DT, Pietrobelli A, Allison DB 2004 Waist circumference percentiles in nationally representative samples of African-American, EuropeanAmerican, and Mexican-American children and adolescents. J Pediatr 145:439-444

59. Despres JP, Couillard C, Gagnon J, Bergeron J, Leon AS, Rao DC, Skinner JS, Wilmore JH, Bouchard C 2000 Race, visceral adipose tissue, plasma lipids, and lipoprotein lipase activity in men and women: the Health, Risk Factors, Exercise Training, and Genetics (HERITAGE) family study. Arterioscler Thromb Vasc Biol 20:1932-1938

60. Owens S, Gutin B, Barbeau P, Litaker M, Allison J, Humphries M, Okuyama T, Le NA 2000 Visceral adipose tissue and markers of the insulin resistance syndrome in obese black and white teenagers. Obes Res 8:287-293

61. Lemieux S, Despres JP, Moorjani S, Nadeau A, Theriault G, Prud'homme D, Tremblay A, Bouchard C, Lupien PJ 1994 Are gender differences in cardiovascular disease risk factors explained by the level of visceral adipose tissue? Diabetologia 37:757-764

62. Lemieux S, Prud'homme D, Bouchard C, Tremblay A, Despres JP 1993 Sex differences in the relation of visceral adipose tissue accumulation to total body fatness. Am J Clin Nutr 58:463-467

63. Goran MI 1999 Visceral fat in prepubertal children: Influence of obesity, anthropometry, ethnicity, gender, diet, and growth. Am J Hum Biol 11:201-207

64. Kortelainen ML, Sarkioja T 2001 Visceral fat and coronary pathology in male adolescents. Int J Obes Relat Metab Disord 25:228-232

65. Wirth A, Steinmetz B 1998 Gender differences in changes in subcutaneous and intraabdominal fat during weight reduction: an ultrasound study. Obes Res 6:393-399

66. Huang TT, Johnson MS, Figueroa-Colon R, Dwyer JH, Goran MI 2001 Growth of visceral fat, subcutaneous abdominal fat, and total body fat in children. Obes Res 9:283-289

67. Gautier JF, Milner MR, Elam E, Chen K, Ravussin E, Pratley RE 1999 Visceral adipose tissue is not increased in Pima Indians compared with equally obese Caucasians and is not related to insulin action or secretion. Diabetologia 42:28-34 